Document downloaded from:

http://hdl.handle.net/10251/121394

This paper must be cited as:

Soler Fernández, D.; Salandin, A.; Micó, JC. (2018). Lowest thermal transmittance of an external wall under budget,material and thickness restrictions: An integer linear programming approach. Energy and Buildings. 158:222-233.

https://doi.org/10.1016/j.enbuild.2017.09.078

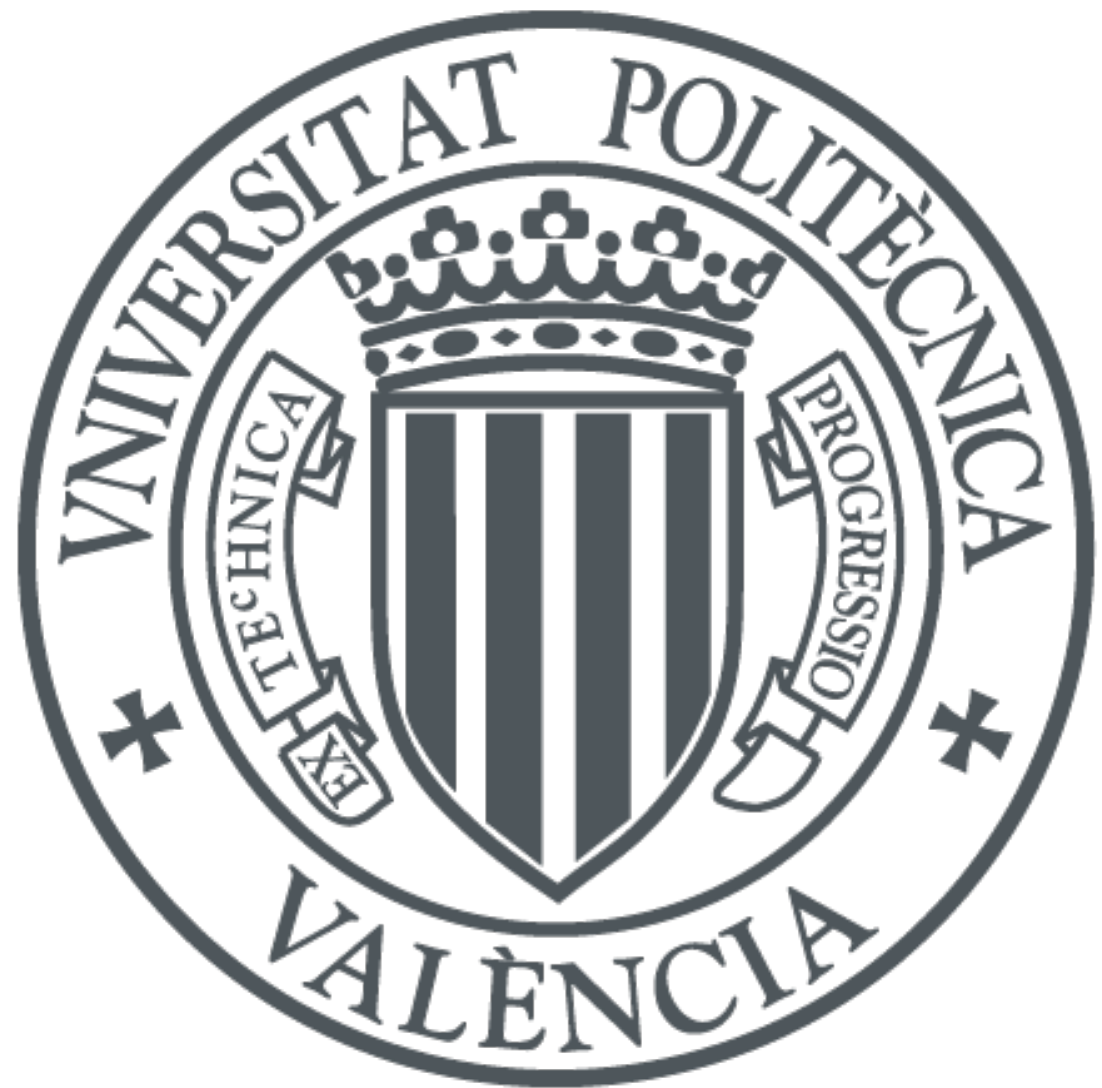

The final publication is available at

http://doi.org/10.1016/j.enbuild.2017.09.078

Copyright Elsevier

Additional Information 


\title{
Lowest thermal transmittance of an external wall under budget, material and thickness restrictions: An Integer Linear Programming approach
}

\author{
David Soler ${ }^{\mathrm{a}}$, Andrea Salandin ${ }^{\mathrm{b}, *}$, Joan C. Micó $^{\mathrm{a}}$ \\ a Instituto Universitario de Matemática Multidisciplinar, Universitat Politècnica de València, Camí de Vera \\ s/n 46022, València, Spain \\ ${ }^{\mathrm{b}}$ Centro de Tecnologías Físicas, Universitat Politècnica de València, Camí de Vera s/n 46022, València, \\ Spain
}

\begin{abstract}
This paper deals with the minimization of a building's external wall thermal transmittance, with the aim of improving the energy efficiency of the building. The wall's thermal transmittance must abide by the current legislation, but also suit the limitations of other construction parameters, mainly budget and thickness, but also time limit, workforce, number and thickness of the layers and availability of materials depending on the approach.

The optimization is achieved formulating an Integer Linear Programming (ILP) problem involving the parameters mentioned above. Therefore, any available ILP solver can be run to obtain the best combination of the different materials and thicknesses for the layers, in order to minimize the thermal transmittance. This paper presents a case study of a common but representative external wall consisting of 6 layers, with more than 670,000 possible combinations of materials and their thicknesses. The study concludes with a comparison of the lowest thermal transmittance obtained for a selection of budget and thickness combinations for the mentioned wall.
\end{abstract}

\section{Keywords}

Thermal transmittance; building envelope; external wall; Integer Linear Programming; building process; budget.

\section{Introduction}

Norms about energy efficiency for buildings in the European Union show an important evolution and development since the approval of the Directive 2010/31/EU [1]. The European Council in March 2010 somehow started the process with a specific action plan for energy efficiency [2] followed by another important and decisive European Council in February 2011. The fact that buildings account for $40 \%$ of the EU's energy consumption [3] and the negative effects related with climate changes have increased people's ecological awareness. A growing demand of a more sustainable and healthy indoor environment is described by Liu et al. [4]. Furthermore, the EU has an important triple energy target for 2020: 1) reducing by $20 \%$ the produced greenhouse gases, 2) covering at least $20 \%$ of energy consumption with renewable energies and 3) improving energy efficiency by reducing the primary energy needs by $20 \%$ [5].

\footnotetext{
* Corresponding autor, Tel: +34963877526 (Ext. 75263)

E-mail addresses: dsoler@mat.upv.es (D. Soler), ansa@upv.es (A. Salandin), jmico@mat.upv.es (J.C. Micó).
} 
According to the definition given by the International Energy Agency [6], energy efficiency can be described as the managing and restraining of growth in energy consumption. A building is more energy efficient if it delivers more services for the same energy input, or the same services for less energy input. There are different strategies for the reduction of energy consumption in buildings: envelope refurbishment, building systems renovation or a combination of both.

The building envelope itself can be described as the physical separator between the interior and exterior of a building. Components of the envelope are typically: walls, floors, roofs, fenestrations and doors. Each component can be categorized as opaque or transparent. The building envelope plays a crucial role for thermal energy transfer and noise protection and should always respond to the local climate. This paper focuses on external walls, which belong to the opaque part of the envelope and help to mitigate the energy consumption of a building [7].

The thermal transmittance $U\left(W m^{-2} K^{-1}\right)$ is a key magnitude in building efficiency. It measures the effectiveness of a building fabric (opaque part and windows) as thermal insulator. The thermal transmittance is given as described by McMullan [8] by Eq. (1):

$$
U=\frac{1}{\frac{1}{h_{\text {int }}}+\sum_{i=1}^{n} \frac{e_{i}}{\lambda_{i}}+\frac{1}{h_{\text {ext }}}}
$$

Where $\lambda_{i}\left(W m^{-1} K^{-1}\right)$ and $e_{i}(m)$ represent the thermal conductivity and the thickness respectively of layer $i$, and $1 / h_{\text {ext }}$ and $1 / h_{\text {int }}\left(m^{2} K W^{-1}\right)$ represent the standard external and internal conductivity respectively for the air layers connected with the envelope, which play a crucial role. Note that the thermal transmittance is considered the inverse of the thermal resistance $R\left(W m^{-2} K^{-1}\right)$.

The literature review on energy and buildings shows many articles taking into account the thermal transmittance of the external walls to reach different targets related with building energy performance. As recent articles, Ascione et al. $[9,10]$ propose a genetic algorithm to obtain, among thousands of combinations, a building envelope satisfying the multi-objective optimization of energy performance of the building and its indoor thermal comfort. Mandilaras et al. [11] studied the thermal performance during one year of an external wall, considering alternative materials in its different layers. Guillén et al. [12] also study the thermal performance of several differently ventilated external walls, along a $24 \mathrm{~h}$ period, with the aim of, among others, reducing the cooling needs of buildings in summer without increasing the total mass of the façade. Eicker et al. [13] present an energetic and economic comparison between energy efficient refurbishment of the building envelope and the integration of renewable solar energy technologies for different climatic conditions. Ahern et al. [14] implement a statistical study on the thermal transmittance values of the building envelope corresponding to the $32 \%$ of the total Irish dwelling stock, in order to use this data for different purposes, such as energy performance certification or as a key input to national building energy consumption models. Finally, the paper by Fokaides and Papadopoulos [15] provides an exhaustive literature review on models to improve the energy performance of buildings.

As far as we know, there is no work in the scientific literature trying to minimize the thermal transmittance of an external wall to be built, beyond the standards of the legal regulations, from the constructor's point of view. The goal is to achieve a higher energy efficiency in the building, taking into account all restrictions involving the construction of that wall: budget, thickness of the wall, number of layers, available materials and 
thicknesses for the different layers, workforce, time limits, final construction cost; etc. Among thousands or millions of combinations of the different materials and thicknesses for the different layers that make up the wall, the aim is to choose the best one to minimize its thermal transmittance without violating any restriction to be taken into account by the construction company.

The use of $U$-value calculators with internal databases, even free access ones, would be very time consuming. They would have to be applied to each combination of layers with external data. Moreover, it would be necessary to check that each combination of layers meets the constructor restrictions.

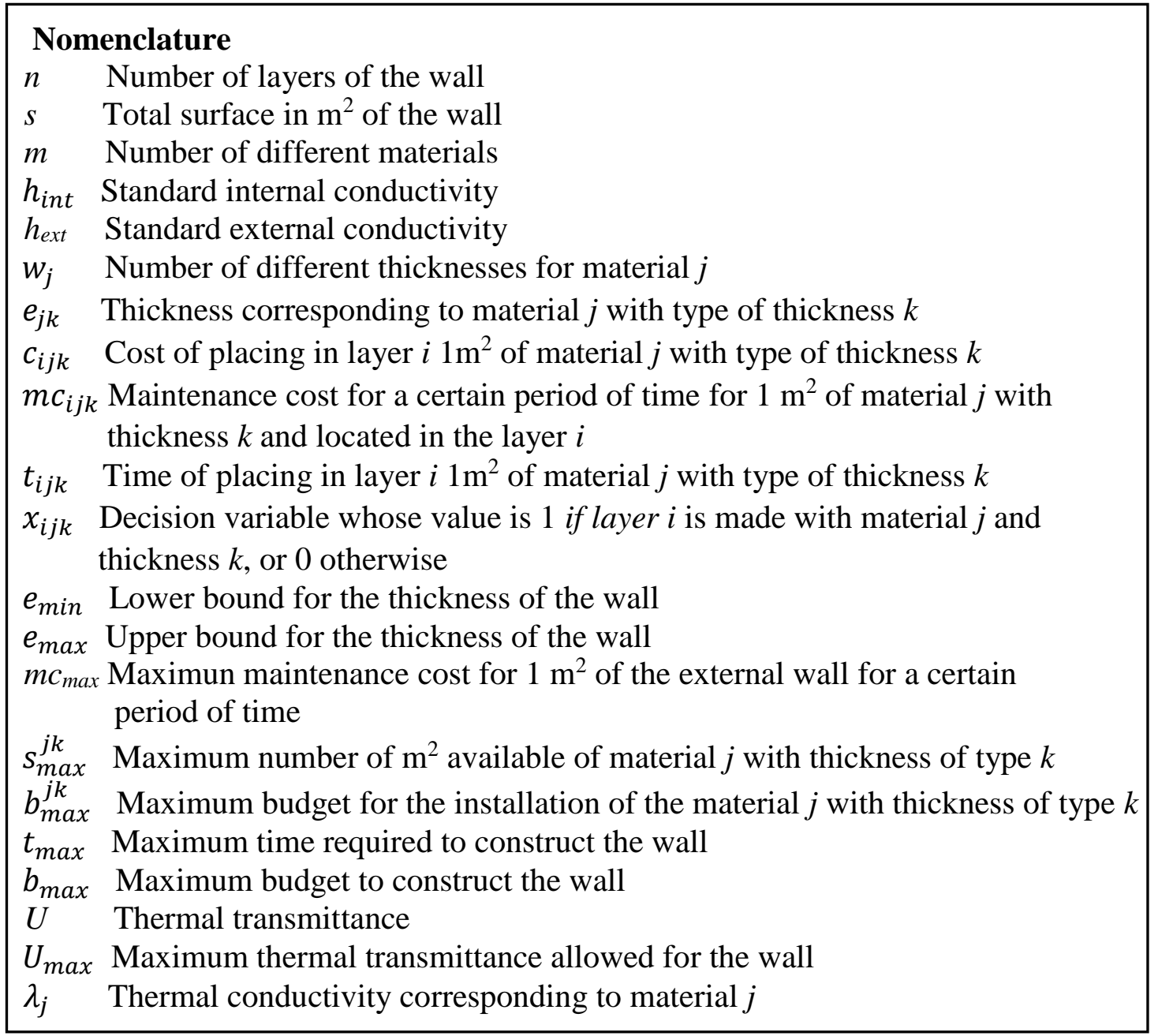

On the other hand, in the field of Operational Research, the Linear Programming (LP) $[16,17]$, and particularly the cases with all integer variables (ILP) and with both integer and continuous variables (mixed case, MILP), have proved their effectiveness to model many real problems in order to optimize an objective function dependent on variables subject to certain linear constraints. Especially interesting is the case of profit maximization or cost minimization of a company that manufactures, manages or transports certain products, taking into account all its frame conditions (workforce, material, machinery, demand, budget, deadline, etc.). Salazar's book [17] shows a large number of these real problems.

LP is increasingly applied in the field of energy and building to solve optimization problems. For instance, Bojic and Trifunovic $[18,19]$ describe the heat transfer in the local heating system by a system of equations that are then linearized. LP is used to retrofit the 
local heating system with additional circulation pumps to provide a greater system control and, therefore, to improve the thermal comfort. Privitera el at. [20] present a LP algorithm that helps to minimize the cost of renewable energy technologies in order to comply with carbon emission reductions. Ashouri et al. [21] use MILP to find the optimal selection and sizing of a smart building system (thermal and electrical storages, heating and cooling systems, and renewable energy sources). More recently, Lindberg et al. [22] investigate cost-optimal solutions for Zero Energy Buildings for different energy indicators with a financial perspective. They use MILP to optimize both the investments (technology choice and size), and the operation of the energy technologies simultaneously. Finally, Ogunjuyigbe et al. [23] also use MILP to allocate electrical power to appliances in residential building with intermittent photovoltaic source. Their objective is to maximize the sub-load points that will be available at each period of the day. With respect to this last paper, it is worth noting that an important case of MILP occurs when there are binary variables, which only take value 0 or 1 at the solution. Such variables can be used to model yes/no decisions, such as turning on or turning off an electrical appliance, as in [23].

The aim of this work is to minimize the thermal transmittance of an external wall subject to construction restrictions, by using ILP where all variables are binary. In this way, any available ILP solver could provide the constructor with the best combination of materials and thicknesses for the different layers, in order to obtain the lowest thermal transmittance, while satisfying the given restrictions. The thermal transmittance would be internally calculated according to the collected data and the legal or constructor constraints.

The reasons why we have decided to apply the ILP technique are the following:

- The increasing and successful use of this technique in the field of energy and buildings, as described above.

- The minimization of $U$ can be obtained with a linear function, and all considered constructor restrictions (budget, time limit, available material, workforce, etc.) can be expressed as linear constraints. This is explained in Section 2.

-The computational results obtained in the case study show that the CPU times needed to solve these problems, are considerably small, taking into account that the ILP solver finds the optimal solution or decides that there is no feasible solution. Although ILP problems have generally exponential complexity, these short running times discourage the testing of heuristic algorithms of polynomial complexity such as genetics (even if they consume less time). They do not guarantee the optimal solution and if they do not find a feasible solution, this does not guarantee that the problem is infeasible (except for an exhaustive study of the solutions, implying a non-polynomial complexity).

The rest of this paper is organized as follows: Section 2 describes the problem in its general form. Section 3 presents the case study for a representative constructive solution consisting of 6 layers, with the results of the ILP application. Finally, Section 4 shows the conclusions. Some appendices are given with an exhaustive exposition of the chosen materials and its characteristics as well as the optimal transmittance in each scenario.

\section{Problem definition and formulation}

In this section, the problem of minimizing the thermal transmittance of an external wall subject to certain construction restrictions, is modeled as an ILP problem. This metric should therefore be the objective function of the ILP problem. 
Taking into account the nomenclature given in the previous table, the variables of the ILP problem are $x_{i j k}$, which are decision variables as in [23], and whose value are 1 if layer $i$ is made with material $j$ and thickness $k$, or 0 otherwise, $i \in\{1, \ldots, n\}, j \in\{1, \ldots, m\}, k \in$ $\left\{1, \ldots, w_{j}\right\}$. It is important to stress that $k$ does not indicate the measure of the thickness but the type of thickness. Note also that layers will be enumerated from outside to inside.

The thermal transmittance of the wall is therefore given by Eq. (2):

$$
U=\frac{1}{\frac{1}{h_{\text {int }}}+\sum_{i=1}^{n} \sum_{j=1}^{m} \sum_{k=1}^{w_{j}} \frac{e_{j k}}{\lambda_{j}} x_{i j k}+\frac{1}{h_{e x t}}}
$$

Nonetheless, it is evident that $U$ is not a linear function of variables $x_{i j k}$, so it cannot be the objective function of the ILP problem. However, $h_{i n t}, h_{e x t}, e_{j k}$ and $\lambda_{j}$ are constant for all the involved subscripts. It is easy to see that minimizing $U$ is equivalent to maximizing the triple summation given in the denominator (the thermal resistance) of $U$, which is certainly a linear function of binary variables $x_{i j k}$. Hence, the objective function of the ILP problem, that must be maximized, will be:

$$
\sum_{i=1}^{n} \sum_{j=1}^{m} \sum_{k=1}^{w_{j}} \frac{e_{j k}}{\lambda_{j}} x_{i j k}
$$

The restriction set of this ILP problem represents the usual limitations to build an external wall, but this set can be expanded, reduced or modified, according to the particular conditions or interest of each building in construction, refurbishment or life-cycle cost approach [24]. Next, we enumerate the chosen conditions:

- The obtained thermal transmittance meets the legal upper bound $U_{\text {max }}$ according to the climate zone. As in the objective function, to ensure a linear constraint, the equivalent Eq. (5) is used. Note that this restriction could be omitted, but in this case, one should check a posteriori that the given solution, if it exists, complies that $U \leq U_{\max }$.

- The total thickness of the wall belongs to the required interval $\left[e_{\min }, e_{\max }\right]$ (Eq. (6)).

- The cost per $\mathrm{m}^{2}$ of the wall will not exceed the budgeted cost $b_{\max }$ (Eq. (7)).

- Each layer is composed by exactly one material with a specific thickness (Eq. (8)). Note that this condition is not obvious to a LP solver.

- The time to build one $\mathrm{m}^{2}$ of the wall will not exceed the established time limit $t_{\max }$ (Eq. (9)).

- The available quantity of each material with its respective thicknesses is limited (Eq. (10)).

- It is also forbidden to spend more money than budgeted for each material and thickness (Eq. (11)).

- It is evident that certain layers cannot admit certain types of material. For instance, it does not make sense to put a waterproof extruded face brick in an intermediate layer, or to put an air gap as a first layer. But even if some options make sense, the conditions imposed on the constructor may forbid these options. The fact that a given material $j$ with a given thickness $k$ is forbidden for a given layer $i$ will be denoted by "ijk-incompatibility" (Eq. (12)).

- Likewise, it could be forbidden to place a material $j$ ' with thickness $k$ ' in the next layer to the one (layer $i$ ) containing the material $j$ with thickness $k$ (this fact will be denoted by $\left(i j k-(i+1) j^{\prime} k^{\prime}\right)$-incompatibility). Therefore, at most one of the two materials with the given 
thickness will appear in the corresponding layer (Eq. (13)). For instance, it does not make sense to put solid concrete block next to a pressed face brick.

- Variables $x_{i j k}$ are defined as binary (Eq. (14)). Remember that, if necessary, these variables can be introduced to the LP solver as nonnegative, integer and upper bounded by 1 .

The ILP formulation of the studied problem is given by Eqs. 4 to 14:

$$
\operatorname{Maximize} \sum_{i=1}^{n} \sum_{j=1}^{m} \sum_{k=1}^{w_{j}} \frac{e_{j k}}{\lambda_{j}} x_{i j k}
$$

s.t.:

$$
\begin{aligned}
& \sum_{i=1}^{n} \sum_{j=1}^{m} \sum_{k=1}^{w_{j}} \frac{e_{j k}}{\lambda_{j}} x_{i j k} \geq \frac{1}{U_{\text {max }}}-\frac{1}{h_{\text {int }}}-\frac{1}{h_{\text {ext }}} \\
& e_{\min } \leq \sum_{i=1}^{n} \sum_{j=1}^{m} \sum_{k=1}^{w_{j}} e_{j k} x_{i j k} \leq e_{\max } \\
& \sum_{i=1}^{n} \sum_{j=1}^{m} \sum_{k=1}^{w_{j}} c_{i j k} x_{i j k} \leq b_{\max } \\
& \sum_{j=1}^{m} \sum_{k=1}^{w_{j}} x_{i j k}=1 \quad \forall i \in\{1, \ldots, n\} \\
& \sum_{i=1}^{n} \sum_{j=1}^{m} \sum_{k=1}^{w_{j}} s t_{i j k} x_{i j k} \leq t_{\max } \\
& \sum_{i=1}^{n} s x_{i j k} \leq s_{\max }^{j k} \quad \forall j \in\{1, \ldots, m\}, k \in\left\{1, \ldots, w_{j}\right\} \\
& \sum_{i=1}^{n} s c_{i j k} x_{i j k} \leq b_{\max }^{j k} \quad \forall j \in\{1, \ldots, m\}, k \in\left\{1, \ldots, w_{j}\right\} \\
& x_{i j k}=0 \quad \forall i j k-i n c o m p a t i b l e \\
& x_{i j k}+x_{(i+1) j^{\prime} k^{\prime}} \leq 1 \quad \forall\left(i j k-(i+1) j^{\prime} k^{\prime}\right)-\text { incompatible } \\
& x_{i j k} \in\{0,1\} \quad \forall i \in\{1, \ldots, n\}, j \in\{1, \ldots, m\}, k \in\left\{1, \ldots, w_{j}\right\}
\end{aligned}
$$

Note that as the maximum value for Eq. (3) gives rise to the minimum value for Eq. (2), once the optimal solution of the previous ILP is obtained, we immediately substitute in Eq. (2) the triple summation by the objective function of the optimal solution. Thus, we obtain the $U$ value of the optimal solution, which is necessarily the minimum $U$ value for all feasible solutions. This is why from now on we will discuss the minimizing of $U$ (our aim) instead of the maximization of the triple summation given by Eq. (3).

As stated before, the restriction set of this ILP problem is open to other linear restrictions or to remove or modify existing ones, in order to fulfill other conditions that could be taken into account in specific problems involving the construction of a building envelope. For example, Eqs. 9 and 10 may not be necessary if there are no limitations to the quantity of 
each type of material, or to the time of constructing the external wall. Moreover, if it is already decided that the first layer must be made of, for instance, pressed face brick (let $j_{0}$ be this type of material), and there are several thicknesses for this material, the following constraint would be added:

$$
\sum_{k=1}^{w_{j_{0}}} x_{1 j_{0} k}=1
$$

Similarly, if a certain type of thermal insulation (let $j_{1}$ be this type of material) must appear once among all layers, with the obvious exception of the first and the last layer, we would add constraint:

$$
\sum_{i=2}^{n-1} \sum_{k=1}^{w_{j_{1}}} x_{i j_{1} k}=1
$$

As another example, under availability of the approximate maintenance $\operatorname{cost} m c_{i j k}$ for a certain period of time for $1 \mathrm{~m}^{2}$ of each material $j$, with thickness $k$ and located in the layer $i$ (mainly the external and the internal layer), if the constructor wants to guarantee that the maintenance cost of $1 \mathrm{~m}^{2}$ of the external wall will not exceed a certain amount $m c_{\max }$ in that period of time, we could add a constrain similar to the next one:

$$
\sum_{i=1}^{n} \sum_{j=1}^{m} \sum_{k=1}^{w_{j}} m c_{i j k} x_{i j k} \leq m c_{\max }
$$

Finally, we highlight that, although the number of layers has been considered fixed, specific conditions for the variables can change this number of layers. For instance, an intermediate layer could consist of an air gap, with different thicknesses. If an air gap presents zero thickness, we will consider zero cost, zero conductivity and zero construction time. If the LP solver selects for the optimal solution a layer consisting of a zero thickness air gap, the "mathematical wall" shows $n$ layers but the real wall has (at most) $n$ - 1 layers. This situation will appear in the case studied in the next section, where the final number of layers can vary between 4 and 6 .

\section{Case study and results}

In this section, we present a case study consisting of a façade of 6 layers as shown on Fig. 1. This façade is a common, simple but also representative constructive solution as described in the building elements catalog of the Instituto Valenciano de la Edificación [25]. We made it more global and versatile by using different thicknesses, materials and fixing solutions.

\subsection{Data}

Table A1 in Appendix A shows all options of materials and thicknesses for the 6 layers, with their corresponding conductivity, cost per $\mathrm{m}^{2}$ and variable name in the ILP problem. Costs are taken from the cost generator website of CYPE Ingenieros [26]. Costs always 
include materials, staff and site facilities. Ten-year maintenance costs are also available but they will not be considered as our approach only includes construction costs. Those costs could be adapted for a life-cycle costs comparison and used as input data for another optimization problem.

The external coating $(\mathrm{eC})$ shows eight options with 2 kinds of plaster, different plates and also, an absence of this first layer, depending on the configuration of the second one. For the second layer, the external panel (eP), five options are included: solid brick, concrete block, face brick and pressed face brick in 2 dimensions. Note that the 3 last options can only occur together with the option of no presence of external coating, which implies the existence of Eq. 13 in the ILP formulation. The air gap (aG) shows 3 different configurations and 9 options: light ventilated air gap (from 3 to $10 \mathrm{~cm}$ ), not ventilated air gap (4 options) and absence of air gap. Note that air-gaps play a very important role in thermal insulation but also in moisture control [12]. Nevertheless, the absence of air gap or ventilation is also a common constructive solution for external walls. Up to 6 insulation materials (tI) have been included for layer 4, with different thicknesses (from 0.015 to 0.08 $\mathrm{m}$ ) and 3 fixing methods (dots, adhesive mortar or mechanical fixing). Values for thermal conductivity ranges from 0.036 to $0.09 \mathrm{Wm}^{-1} \mathrm{~K}^{-1}$. Conventional (mineral wool, extruded and expanded polystyrene, sandwich panel) and alternative (cork, wood chips) materials, as classified by Schiavoni et al. [27], have been chosen. Moreover, the Basic Document for Energy Saving of the Spanish Technical Building Act [28] considers thermal insulating material with lower thermal conductivity than $0.06 \mathrm{Wm}^{-1} \mathrm{~K}^{-1}$ and thermal resistance greater than $0.25 \mathrm{~m}^{2} \mathrm{KW}^{-1}$. Layer 5 represents the internal panel (iP) with eight options showing different dimensions and perforations (air brick, perforated brick, solid block also with expanded clay). Finally, the internal coating (layer $6, \mathrm{iC}$ ) is made by plaster in 4 different options (8 to $14 \mathrm{~mm}$ ).

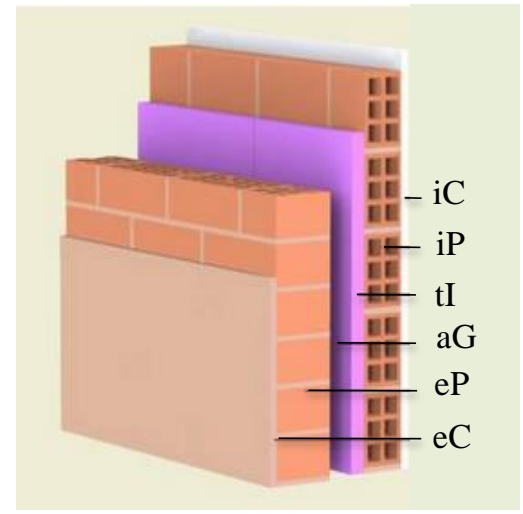

1: eC, external coating: 2 plaster types, plates, absence.

2: eP, external panel: solid brick, concrete block, face brick, 2 pressed face brick.

3: aG, air gap: light ventilated, not ventilated, absence.

4: tI, thermal insulation: 6 materials, 4 thicknesses,

3 fixing methods.

5: iP, internal panel: solid, air, or perforated brick.

6: iC, internal coating: plaster with 4 thicknesses.

Fig.1. Constructive detail of the case study, with options for each layer.

A total amount of 671,328 combinations for this external wall are possible. Note that the number of layers of this wall can vary between 4 and 6 because the external coating is optional (depending on the external panel) as well as the air gap.

Furthermore, the recommended thermal resistance for the air layers close to the external and internal surfaces are: $1 / h_{\text {ext }}=0,04 \mathrm{~m}^{2} \mathrm{KW} \mathrm{W}^{-1}$ and $1 / h_{\text {int }}=0,13 \mathrm{~m}^{2} \mathrm{KW}^{-1}$ as indicated in the Spanish Technical Act (CTE), Basic Document of Energy Saving (DB_HE) [28]. 
On the other hand, we have considered that the total thickness of the wall can vary between 0.24 and $0.63 \mathrm{~m}$ in intervals of $1 \mathrm{~cm}$. We have also considered a budget to construct $1 \mathrm{~m}^{2}$ of wall limited to an amount ranging between $€ 85$ and $€ 190$, with intervals of $€ 5$. The aim is to find the lowest thermal transmittance wall for each combination of wall thickness and budget. As there are 45 intervals of $1 \mathrm{~cm}$ and 22 budgets, 990 ILP problems must be solved.

Due to the amount of problems to be solved and the huge amount of possible solutions, there was a need to use a tool for comparing options satisfying construction costs while internally obtaining the lowest thermal transmittance $U$ as a key measurable magnitude directly involved in the building process. The lower the value of thermal transmittance, the better insulated is the building. Table 1 shows the maximal reference values for thermal transmittance $U_{\max }$ in winter time, according to the Basic Document for Energy Saving of the Spanish Technical Building Act [28] and depending on the 5 climate zones (A to E).

Table 1

$U_{\max }$ values according to the Basic Document for Energy Saving of the Spanish Technical Building Act.

\begin{tabular}{|c|c|c|c|c|c|}
\hline \multirow{2}{*}{ Parameter } & \multicolumn{5}{|c|}{ WINTER CLIMATE ZONE } \\
\hline & $\mathbf{A}$ & B & $\mathbf{C}$ & $\mathbf{D}$ & $\mathbf{E}$ \\
\hline $\begin{array}{c}\text { Thermal transmittance of walls and elements in contact } \\
\text { with ground }\left(\mathrm{W} / \mathrm{m}^{2} \cdot \mathrm{K}\right)\end{array}$ & 1.25 & 1.00 & 0.75 & 0.60 & 0.55 \\
\hline $\begin{array}{c}\text { Thermal transmittance of roof and horizontal elements } \\
\text { in contact with air }\left(\mathrm{W} / \mathrm{m}^{2} \cdot \mathrm{K}\right)\end{array}$ & 0.80 & 0.65 & 0.50 & 0.40 & 0.35 \\
\hline Thermal transmittance of transparent part $\left(\mathrm{W} / \mathrm{m}^{2} \cdot \mathrm{K}\right)$ & 5.70 & 4.20 & 3.10 & 2.70 & 2.50 \\
\hline Air permeability of transparent part $\left(\mathrm{m}^{3} / \mathrm{h} \cdot \mathrm{m}^{2}\right)$ & $\leq 50$ & $\leq 50$ & $\leq 27$ & $\leq 27$ & $\leq 27$ \\
\hline
\end{tabular}

\subsection{Results}

Mathematica 11.0 [29] was chosen to solve the 990 ILP problems cited above. It is a widely used tool to solve engineering, physical and mathematical problems. It was chosen for three reasons: It has several functions to solve ILP problems; it has its own programming language (useful to solve the 990 ILP problems and to output their results with a single execution) and due to its interface, which allows viewing on the screen both the formulation of the problem and the solution given by the tool.

Mathematica was run on a PC Intel ${ }^{\circledR}$ Core ${ }^{\mathrm{TM}} \mathrm{I} 7-6700$ with 4 processors, $3.46 \mathrm{GHz}$ and 8GB RAM. 752 out of the 900 ILP problems were found feasible, while the remaining 238 problems were found infeasible.

It is important to highlight that, with respect to the set of 752 feasible problems, the average CPU time to obtain the optimal solution was 0.0234 seconds, with a maximum value of 0.0781 seconds and a minimum value of 0 seconds, which according to Mathematica's assumption means that the calculation takes no measurable CPU time. Regarding the set of 238 infeasible problems, the average CPU time to determine that a problem was infeasible was 10.4120 seconds, with a maximum value of 11.6562 seconds and a minimum value of 10.2812 seconds.

As an ILP problem has exponential complexity from a theoretical point of view, we believe that the running times obtained with Mathematica are excellent and very stable for feasible problems, and also very reasonable and very stable for the infeasible problems, due to the branch-and-bound method used and to the large amount of possible combinations. Therefore, these CPU time results justify the choice of the ILP exact procedure, and the tool Mathematica, without underestimating other available ILP solvers. 
Note that for a budget of $85 € / \mathrm{m}^{2}$, all the 45 ILP problems were infeasible. That is, none of the 671,328 combinations costs less than or equal to $85 € / \mathrm{m}^{2}$. Table B1 in Appendix B shows the minimum thermal transmittance achieved for each pair (thickness (row), budget (column)), except for the budget of $85 € / \mathrm{m}^{2}$. We started by $90 € / \mathrm{m}^{2}$ in order to avoid the first blank column, since a blank means that the corresponding problem has no solution. Note that to show a table of reasonable size, $U$ values have been rounded to three decimal places. A first view of the table may give the impression that there are many repeated $U$ values and consequently few different optimal combinations of layers. This is not the case since several optimal combinations of materials have a coincident $U$ when rounded to three decimal places.

As expected, given a fixed thickness, the thermal transmittance decreases as the budget increases, although the variability of $U$ is usually only a few decimals. As significant data, for a thickness of [0.24,0.26], the problem is infeasible with a budget of less than $125 € / \mathrm{m}^{2}$, but from $125 € / \mathrm{m}^{2}$, the $U$ value is almost the double in the interval [0.24,0.25] than in the interval $[0.25,0.26]$, implying that $0.25 \mathrm{~m}$ is a first important thickness limit in this case. At the other end of the table, for large thicknesses, the problem is only feasible for high budgets, but given the feasibility of the problem, the optimal $U$ value is very small. For instance, for the interval [0.67,0.69], the problem is only feasible for a budget of $190 € / \mathrm{m}^{2}$, with an optimal low $U$ of $0.205 \mathrm{Wm}^{-2} \mathrm{~K}^{-1}$.

Another expected trend is that given a budget, the thermal transmittance also decreases as the thickness increases, but once a certain thickness is exceeded, the problem becomes infeasible. For example, for a budget of $90 € / \mathrm{m}^{2}$ the problem starts to be feasible in the interval $[0.27,0.28]$ and ends to be feasible in the interval $[0.46,0.47]$, with a minimum $U$ value varying from $0.706 \mathrm{Wm}^{-2} \mathrm{~K}^{-1}$ to $0.224 \mathrm{Wm}^{-2} \mathrm{~K}^{-1}$. At the other end of the table, for a budget of $190 € / \mathrm{m}^{2}$ the problem is feasible for all the considered intervals, with a minimum $U$ value varying from $1.332 \mathrm{Wm}^{-2} \mathrm{~K}^{-1}$ in $[0.24,0.25]$ to $0.205 \mathrm{Wm}^{-2} \mathrm{~K}^{-1}$ in $[0.68,0.69]$. Note that $1.332 \mathrm{Wm}^{-2} \mathrm{~K}^{-1}$ is not an allowed $U$ for any climate zone (see Table 1 ).

Figs. 2 and 3 show the variation of representative optimal $U$ values depending on budget and thickness respectively.

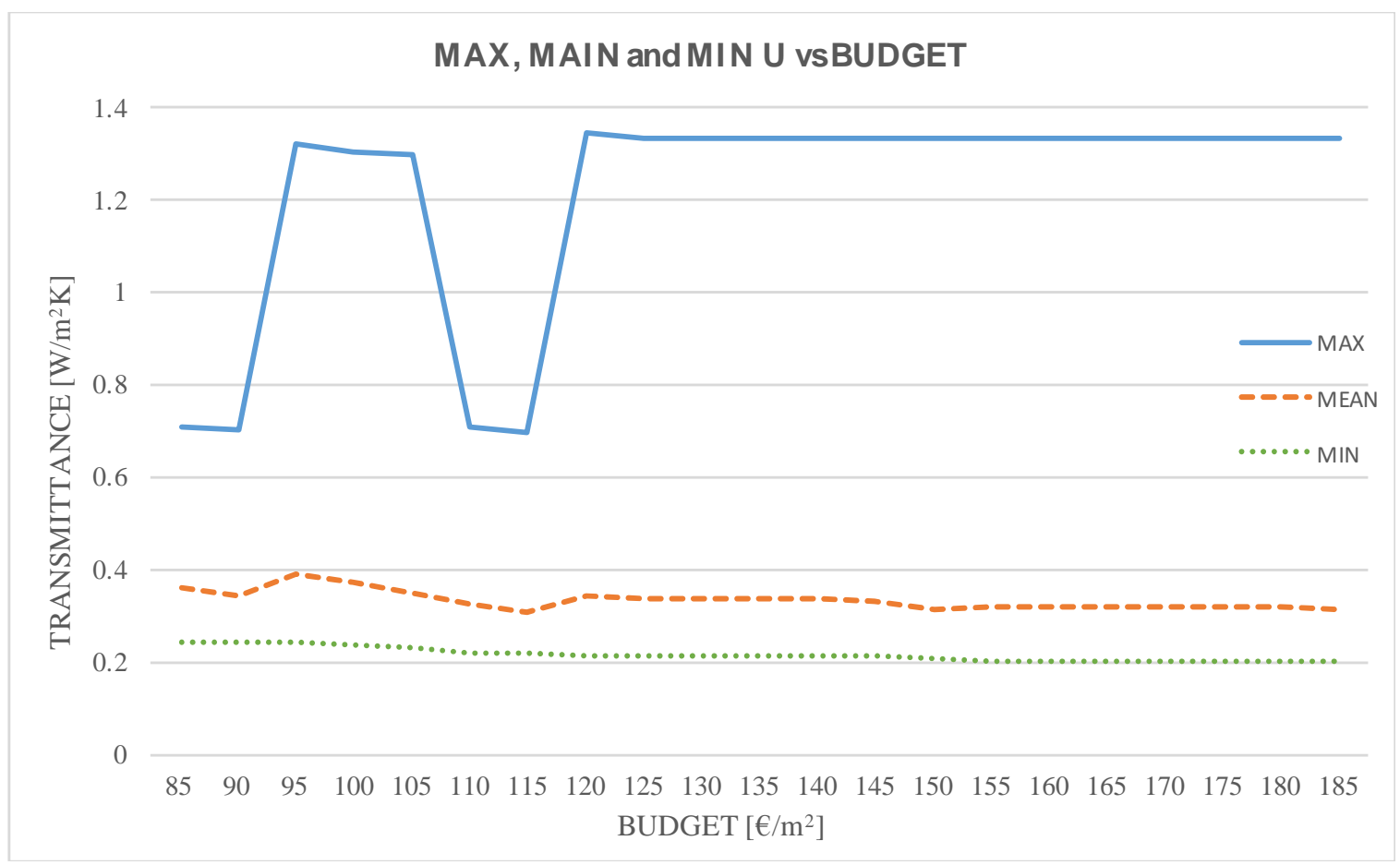


Fig.2. Minimum, mean and maximum values for optimal $U$ vs budget.

They show the tendencies explained above but with significant lack of information, since they cannot compute the cases in which the problem has been infeasible. For example, for low budgets (ranging between $90 € / \mathrm{m}^{2}$ and $115 € / \mathrm{m}^{2}$ ) almost half of the thickness/budget combinations are impossible, especially for large thicknesses.

Moreover, given a budget, in the first interval where the problem is feasible, the optimal value of $U$ is usually very large compared to the successive intervals. This explains the difference between the curve of maximum values for optimal $U$ and the other two curves in both figures.

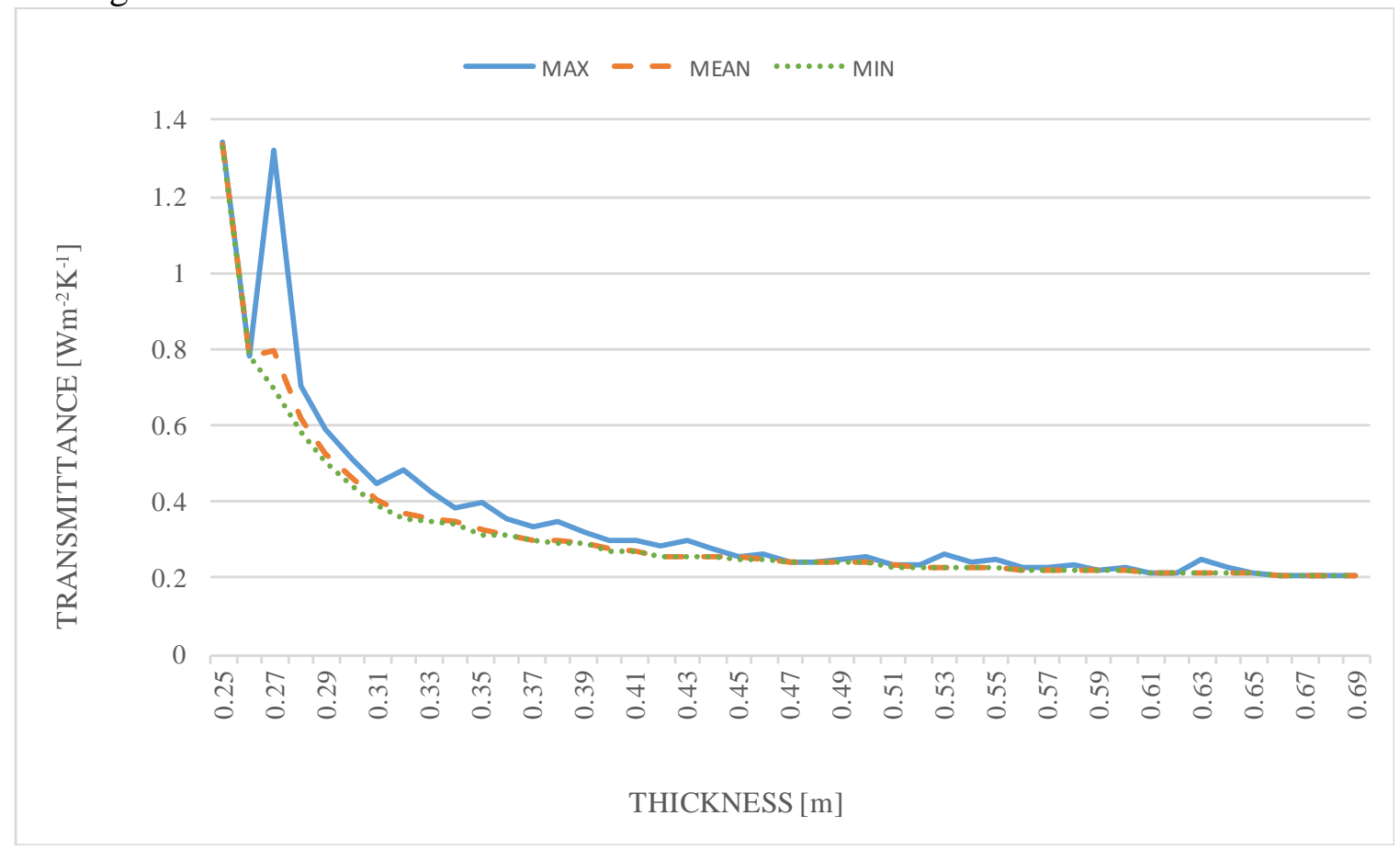

Fig. 3. Minimum, mean and maximum values for optimal $U$ vs thickness.

Fig. 4 shows radar diagrams for six of the most representative thickness intervals, according to the results given in Table B1. Radar diagrams can be very effective to show jointly the behavior of optimal $U$ values depending on thickness and budget for the external wall, especially because these diagrams do show the impossibility of a scenario. Values for $U$ range from 0 up to $1.4 \mathrm{Wm}^{-2} \mathrm{~K}^{-1}$ (concentric circles) while budget starts with $90 € / \mathrm{m}^{2}$ reaching clockwise the maximum value of $190 € / \mathrm{m}^{2}$.

In these diagrams, the absence of stroke in a circular sector means that the problem is infeasible in that sector (e.g. in thickness [0.25,0.26]). A stroke near the center of the circle means lower values of reached $U$ in the corresponding sector (e.g. in thickness [0.46-0.47]), and peaks indicates big differences for similar budgets (e.g. in thickness [0.26-0.27]). We present next some comments for each representative interval of thickness.

- For interval [0.24,0.25] there is no feasible solution for a budget less than $125 € / \mathrm{m}^{2}$, and for $125 € / \mathrm{m}^{2}$ or more, the minimum value for $U$ is always about $1.33 \mathrm{Wm}^{-2} \mathrm{~K}^{-1}$. This value doesn't match the requirements for any climate zone A to $\mathrm{E}$.

- For interval [0.25,0.26] we have a similar behavior as for interval $[0.24,0.25]$ with infeasible solution for a budget less than $125 € / \mathrm{m}^{2}$ but a lower and constant value of transmittance of $0.782 \mathrm{Wm}^{-2} \mathrm{~K}^{-1}$ almost acceptable for climate zone $\mathrm{C}$. 
- For interval $[0.26,0.27]$ there is no feasible solution for a budget less than $100 € / \mathrm{m}^{2}$, between $100 € / \mathrm{m}^{2}$ and $110 € / \mathrm{m}^{2}$ the solutions exist with a minimum value for $U 1.30 \mathrm{Wm}^{-}$ ${ }^{2} \mathrm{~K}^{-1}$, but for budgets greater than $110 € / \mathrm{m}^{2}$, the minimum value for $U$ is almost half, about $0.70 \mathrm{Wm}^{-2} \mathrm{~K}^{-1}$, acceptable for climate zone $\mathrm{C}$.

- For interval $[0.35,0.36]$ all budgets have feasible and stable solution, with minimum value for $U$, about $0.31 \mathrm{Wm}^{-2} \mathrm{~K}^{-1}$ except for the minimum budget $\left(90 € / \mathrm{m}^{2}\right)$ for which the minimum $U$ value is $0.358 \mathrm{Wm}^{-2} \mathrm{~K}^{-1}$, acceptable for all climate zone A to $\mathrm{E}$.

- Interval $[0.46,0.47]$ is the only interval in which all budgets have feasible solution with approximately the same and very low minimum value for $U$, about $0.242 \mathrm{Wm}^{-2} \mathrm{~K}^{-1}$.

- For interval $[0.66,0.67]$ there is no feasible solution for a budget les than $155 € / \mathrm{m}^{2}$, but for budgets greater than or equal to $155 € / \mathrm{m}^{2}$, the optimal solution is always the same $(U$ value of $0.204 \mathrm{Wm}^{-2} \mathrm{~K}^{-1}$ ).

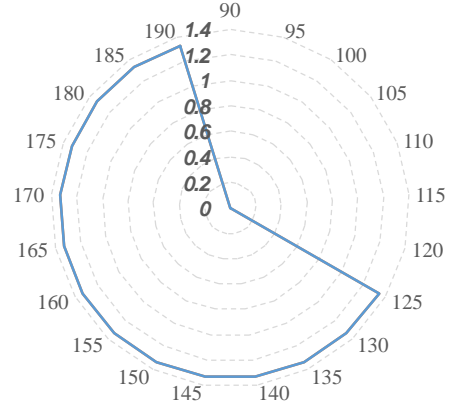

THICKNESS $[0.24,0.25 \mathrm{~m}]$

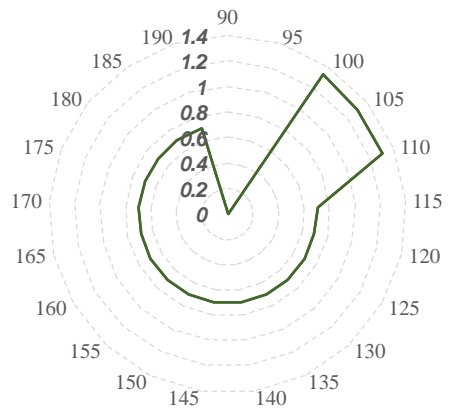

THICKNESS $[0.26,0.27 \mathrm{~m}]$

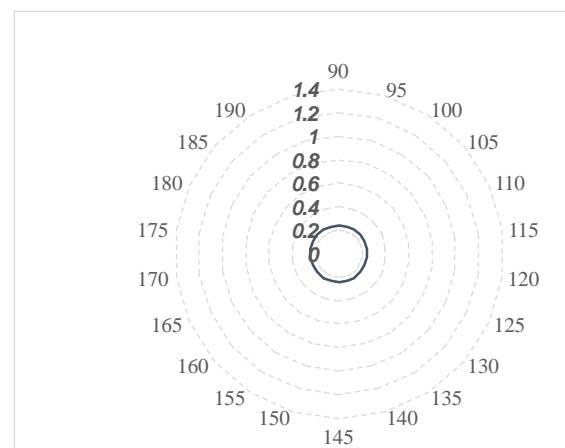

THICKNESS $[0.46,0.47 \mathrm{~m}]$

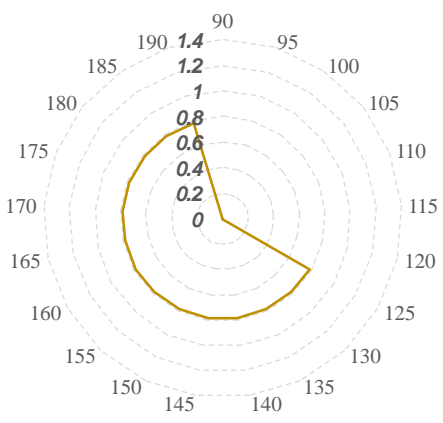

THICKNESS $[0.25,0.26 \mathrm{~m}]$

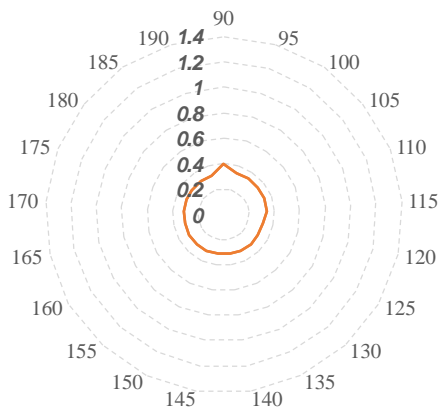

THICKNESS $[0.35,0.36 \mathrm{~m}]$

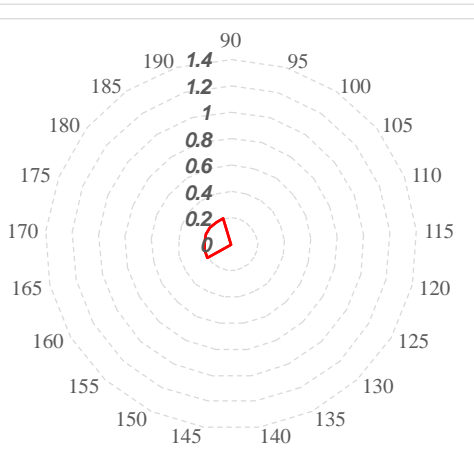

THICKNESS $[0.66,0.67 \mathrm{~m}]$

Fig. 4. Reached $U$ value vs budget for different thicknesses.

As stated before, Table B1 in Appendix B shows the minimum thermal transmittance achieved for each one of the 945 pairs (thickness (row), budget (column)) for which the problem has a feasible solution. Obviously, for each optimal solution, in addition to its 
thermal transmittance, Mathematica provides the values of the binary variables, so it is easy to see which is the chosen material and its thickness for each one of the six layers in the solution with minimum thermal transmittance.

We omit the exhaustive exposure of the material and thickness for each one of the 6 layers in the hundreds of different optimum solutions, as this would probably give rise to a large number of additional pages. Instead, through Table 2 we show all the data corresponding to the best solution obtained under 7 different scenarios, which represent the extreme cases: minimum budget $\left(90 € / \mathrm{m}^{2}\right)$; minimum thickness (interval $[0.24,0.25]$ ); maximum budget (up to $190 € / \mathrm{m}^{2}$ ); maximum thickness (interval [0.68,0.69]); given the minimum budget, take the minimum possible thickness; given the minimum thickness, take the minimum possible budget; and finally, the combination budget/thickness that has obtained the optimal solution with lowest thermal transmittance.

Table 2

Optimal solution for 7 scenarios of interest.

\begin{tabular}{|c|c|c|c|c|c|c|c|}
\hline & $\begin{array}{l}\text { Minimum } \\
\text { budget }\end{array}$ & $\begin{array}{l}\text { Minimum } \\
\text { thickness }\end{array}$ & $\begin{array}{l}\text { Maximum } \\
\text { budget }\end{array}$ & $\begin{array}{l}\text { Maximum } \\
\text { thickness }\end{array}$ & $\begin{array}{l}\text { Minimum } \\
\text { budget / } \\
\text { minimum } \\
\text { thickness }\end{array}$ & $\begin{array}{l}\text { Minimum } \\
\text { thickness / } \\
\text { minimum } \\
\text { budget }\end{array}$ & Minimum $U$ \\
\hline Budget & 90 & 130 & 190 & 190 & 90 & 125 & 190 \\
\hline $\begin{array}{l}\text { Thickness } \\
\text { interval }\end{array}$ & {$[0.46,0.47]$} & {$[0.24,0.25]$} & {$[0.66,0.67]$} & {$[0.68,0.69]$} & {$[0.27,0.28]$} & {$[0.24,0.25]$} & {$[0.66,0.67]$} \\
\hline Minimum $U$ & 0.243525 & 1.33167 & 0.203537 & 0.204624 & 0.706436 & 1.345458 & 0.203537 \\
\hline Exact cost & 89.71 & 125.22 & 166.89 & 189.18 & 89.57 & 123.82 & 166.89 \\
\hline $\begin{array}{l}\text { Exact } \\
\text { thickness }\end{array}$ & 0.463 & 0.25 & 0.664 & 0.682 & 0.278 & 0.248 & 0.664 \\
\hline Layer 1 & $\begin{array}{l}\text { Reg. plas. } \\
0.013\end{array}$ & $\begin{array}{l}\text { No extern. } \\
\text { coating }\end{array}$ & $\begin{array}{l}\text { Ther. plas. } \\
0.020\end{array}$ & $\begin{array}{l}\text { Limestone } \\
\text { (Brasil) }\end{array}$ & $\begin{array}{l}\text { Reg. plas. } \\
0.013\end{array}$ & $\begin{array}{l}\text { No extern. } \\
\text { coating }\end{array}$ & $\begin{array}{l}\text { Ther. plas. } \\
0.020\end{array}$ \\
\hline Layer 2 & $\begin{array}{l}\text { Concrete } \\
\text { block }\end{array}$ & $\begin{array}{l}\text { Waterpr. } \\
\text { face brick }\end{array}$ & $\begin{array}{l}\text { Concrete } \\
\text { block }\end{array}$ & $\begin{array}{l}\text { Concrete } \\
\text { block }\end{array}$ & Solid brick & $\begin{array}{l}\text { Waterpr. face } \\
\text { brick }\end{array}$ & $\begin{array}{l}\text { Concrete } \\
\text { block }\end{array}$ \\
\hline Layer 3 & $\begin{array}{l}\text { Light vent. } \\
\text { a.g. } 0.10\end{array}$ & $\begin{array}{l}\text { Without air } \\
\text { gap }\end{array}$ & $\begin{array}{l}\text { Light vent. } \\
\text { a.g. } 0.10\end{array}$ & $\begin{array}{l}\text { Light vent. } \\
\text { a.g. } 0.10\end{array}$ & $\begin{array}{l}\text { Without air } \\
\text { gap. }\end{array}$ & $\begin{array}{l}\text { Without air } \\
\text { gap. }\end{array}$ & $\begin{array}{l}\text { Light vent. } \\
\text { a.g. } 0.10\end{array}$ \\
\hline Layer 4 & $\begin{array}{l}\text { Exp. poly. } \\
\text { dots } 0.08\end{array}$ & $\begin{array}{l}\text { Wood chips } \\
0.015\end{array}$ & $\begin{array}{l}\text { Exp. poly. } \\
\text { dots } 0.08\end{array}$ & $\begin{array}{l}\text { Exp. poly. } \\
\text { dots } 0.08\end{array}$ & $\begin{array}{l}\text { Exp. poly. } \\
\text { dots } 0.03\end{array}$ & $\begin{array}{l}\text { Wood chips } \\
0.015\end{array}$ & $\begin{array}{l}\text { Exp. poly. } \\
\text { dots } 0.08\end{array}$ \\
\hline Layer 5 & $\begin{array}{l}\text { Air brick } \\
33 \cdot 16 \cdot 11\end{array}$ & $\begin{array}{l}\text { Air brick } \\
33 \cdot 16 \cdot 11\end{array}$ & $\begin{array}{l}\text { E.c.l. concr. } \\
\text { block } 0.30\end{array}$ & $\begin{array}{l}\text { E.c.l. concr. } \\
\text { block } 0.30\end{array}$ & $\begin{array}{l}\text { Air brick } \\
33 \cdot 16 \cdot 11\end{array}$ & $\begin{array}{l}\text { Air brick } \\
33 \cdot 16 \cdot 11\end{array}$ & $\begin{array}{l}\text { E.c.l. concr. } \\
\text { block } 0.30\end{array}$ \\
\hline Layer 6 & $\begin{array}{l}\text { Plaster } \\
0.010\end{array}$ & $\begin{array}{l}\text { Plaster } \\
0.010\end{array}$ & $\begin{array}{l}\text { Plaster } \\
0.014\end{array}$ & $\begin{array}{l}\text { Plaster } \\
0.012\end{array}$ & $\begin{array}{l}\text { Plaster } \\
0.010\end{array}$ & $\begin{array}{l}\text { Plaster } \\
0.008\end{array}$ & $\begin{array}{l}\text { Plaster } \\
0.014\end{array}$ \\
\hline
\end{tabular}

As the most relevant data shown by Table 2, with our selection of materials and thicknesses, the lowest possible $U$ value for an external wall is $0.2035 \mathrm{Wm}^{-2} \mathrm{~K}^{-1}$, which is achieved for a cost of $€ 166.89$ per $\mathrm{m}^{2}$ and a thickness of $0.664 \mathrm{~m}$. Note that this $U$ value is very small and therefore is useful for every climate zone (see Table 1), but if the builder has a very limited budget, an $U$ value of $0.2435 \mathrm{Wm}^{-2} \mathrm{~K}^{-1}$ (only three hundredths more, but also useful for every climate zone), can be achieved with cost $€ 89.71$ and a thickness of $0.466 \mathrm{~m}$. This is a very important result of this study: the building company can considerably reduce the cost of the external wall with a very low increase of the thermal transmittance, just choosing the right materials and thicknesses. On the other hand, a very thin wall (in the range $[0.24,0.25]$ ) gives rise to high $U$ values (more than $1.33 \mathrm{Wm}^{-2} \mathrm{~K}^{-1}$ ) incompatibles with climate zones A to E) and high final construction costs.

\section{Conclusion}

This paper presents an ILP exact procedure to obtain the lowest thermal transmittance corresponding to an external wall to be built, taking into account the limitations that the builder has to face: current legislation in relation to thermal transmittance, budget, 
thickness, time limit, workforce, number of layers, available materials, etc. A case study consisting of a façade of 6 layers, which is a representative constructive solution, has also been presented. In this study, 990 ILP problems corresponding to the combinations of 45 intervals of thickness and 22 budgets have been solved, to find in each case the minimum thermal transmittance combination of materials and thicknesses for the 6 layers among 671,328 possible combinations. Mathematica has been used as ILP solver in this case study with very good and stable CPU times. That confirms the appropriateness of the approach.

The aim of this work is to provide the builder with a tool that allows him to analyze different scenarios for the construction of the wall, in order to contribute to a better energy efficiency of the building and adaptability to the climate zone. The study shows that an adequate selection of materials, a small variation in the thickness of the wall or a small increase in the budget, among other factors, can reduce considerably the thermal transmittance of the wall, and therefore improve the energy efficiency of the building throughout its life. The selection of the suitable materials and measures for this purpose is not an easy task since thousands or even millions of different options may exist for each scenario. Our procedure, together with the existence of LP solvers -including free access ones- can help to this aim.

As a future work, this ILP modelization can be extended in several aspects. For example, the behavior of the roof or the complete envelope could also be studied. Nonlinear constraints could also be included, since some software containing LP solvers also incorporate the resolution of nonlinear programming problems. Furthermore, a system could be developed in which the ILP is able to determine by itself the adequate number of layers.

Finally, a variation of the procedure presented here could be useful for the optimal selection of both internal and external layers in the refurbishment of houses, optimizing thermal comfort without neglecting the economic criteria.

\section{Acknowledgement}

This work was partially supported by the "Ministerio de Economía y Competitividad, Programa Estatal de Investigación, Desarrollo e Innovación Orientada a los Retos de la Sociedad, Proyectos I+D+I 2014”, Spain, under Grant TEC2014-52690-R. 


\section{Appendix A. Data of the chosen materials}

\section{Table A1}

Layers and chosen materials with their characteristics.

\begin{tabular}{|c|c|c|c|c|c|}
\hline Layer & Material & Thickness[m] & $\begin{array}{l}\text { Conductivity } \lambda \\
{\left[\mathrm{W} / \mathrm{mK}^{-1}\right]}\end{array}$ & Cost $\left[€ / \mathbf{m}^{2}\right]$ & $\begin{array}{l}\text { Variable } \\
\text { name }\end{array}$ \\
\hline \multirow[t]{17}{*}{ 1a. External coating } & Regular plaster & 0.013 & 0.93 & 18.44 & $x_{111}$ \\
\hline & & 0.015 & 0.93 & 19.44 & $x_{112}$ \\
\hline & & 0.018 & 0.93 & 20.44 & $x_{113}$ \\
\hline & & 0.020 & 0.93 & 21.44 & $x_{114}$ \\
\hline & Thermal plaster & 0.013 & 0.67 & 25.81 & $x_{121}$ \\
\hline & & 0.015 & 0.67 & 27.22 & $x_{122}$ \\
\hline & & 0.018 & 0.67 & 28.62 & $x_{123}$ \\
\hline & & 0.020 & 0.67 & 30.02 & $x_{124}$ \\
\hline & Metallic plate corten & 0.02 & 0.58 & 123.50 & $x_{131}$ \\
\hline & S355J0WP & 0.015 & 0.58 & 114.99 & $x_{132}$ \\
\hline & Metallic plate corten & 0.02 & 0.58 & 123.84 & $x_{141}$ \\
\hline & S355J2WP & 0.015 & 0.58 & 115.24 & $x_{142}$ \\
\hline & Limestone plate (Spain) & 0.04 & 3.5 & 93.07 & $x_{151}$ \\
\hline & (Brasil) & 0.04 & 3.5 & 53.71 & $x_{161}$ \\
\hline & Marble plate (Spain) & 0.03 & 2.09 & $55.51 €$ & $x_{171}$ \\
\hline & (Italy) & 0.03 & 2.09 & 102.33 & $x_{181}$ \\
\hline & Composite plate & 0.04 & 3.38 & 214.02 & $x_{191}$ \\
\hline $\begin{array}{l}\text { 1b. Without External } \\
\text { coating if } 2 b\end{array}$ & & 0 & 0 & 0 & $x_{1101}$ \\
\hline \multirow[t]{2}{*}{ 2a. External panel } & Solid brick & 0.115 & 0.85 & 25.46 & $x_{2111}$ \\
\hline & Concrete block & 0.15 & 0.46 & 22.63 & $x_{2121}$ \\
\hline \multirow[t]{3}{*}{ 2b. External panel } & $\begin{array}{l}\text { Waterproof extruded } \\
\text { face brick }\end{array}$ & 0.115 & 0.76 & 70.65 & $x_{2131}$ \\
\hline & $\begin{array}{l}\text { Pressed face brick } \\
24 \times 12 \times 4\end{array}$ & 0.12 & 0.76 & 109.95 & $x_{2141}$ \\
\hline & $\begin{array}{l}\text { Pressed face brick } \\
24 \times 12 \times 5\end{array}$ & 0.12 & 0.76 & 103.81 & $x_{2151}$ \\
\hline \multirow{4}{*}{$\begin{array}{l}\text { 3a. light ventilated air } \\
\text { gap }\end{array}$} & Air & 0.03 & 0.08 & 0 & $x_{3161}$ \\
\hline & & 0.05 & 0.09 & 0 & $x_{3162}$ \\
\hline & & 0.08 & 0.09 & 0 & $x_{3163}$ \\
\hline & & 0.10 & 0.09 & 0 & $x_{3164}$ \\
\hline \multirow{4}{*}{$\begin{array}{l}3 \mathrm{c} \text { not ventilated air } \\
\text { gap }\end{array}$} & Air & 0.03 & 0.17 & 0 & $x_{3171}$ \\
\hline & & 0.05 & 0.18 & 0 & $x_{3172}$ \\
\hline & & 0.08 & 0.18 & 0 & $x_{3173}$ \\
\hline & & 0.10 & 0.18 & 0 & $x_{3174}$ \\
\hline 3c. without air gap & & 0 & 0 & 0 & $x_{3181}$ \\
\hline
\end{tabular}




\begin{tabular}{|c|c|c|c|c|c|}
\hline \multirow[t]{53}{*}{ 4. Thermal insulation } & \multicolumn{5}{|l|}{ Extruded polystyrene } \\
\hline & Dots & 0.03 & 0.037 & 6.49 & $x_{4191}$ \\
\hline & Adhesive mortar & 0.03 & 0.037 & 8.47 & $x_{4201}$ \\
\hline & Mechanical fixing & 0.03 & 0.037 & 7.99 & $x_{4211}$ \\
\hline & Dots & 0.04 & 0.037 & 7.35 & $x_{4192}$ \\
\hline & Adhesive mortar & 0.04 & 0.037 & 9.33 & $x_{4202}$ \\
\hline & Mechanical fixing & 0.04 & 0.037 & 8.85 & $x_{4212}$ \\
\hline & Dots & 0.05 & 0.037 & 8.23 & $x_{4193}$ \\
\hline & Adhesive mortar & 0.05 & 0.037 & 10.21 & $x_{4203}$ \\
\hline & Mechanical fixing & 0.05 & 0.037 & 9.73 & $x_{4213}$ \\
\hline & Dots & 0.06 & 0.037 & 9.12 & $x_{4194}$ \\
\hline & Adhesive mortar & 0.06 & 0.037 & 11.10 & $x_{4204}$ \\
\hline & Mechanical fixing & 0.06 & 0.037 & 10.62 & $x_{4214}$ \\
\hline & \multicolumn{5}{|l|}{ Mineral wool } \\
\hline & Dots & 0.03 & 0.04 & 7.68 & $x_{4221}$ \\
\hline & Adhesive mortar & 0.03 & 0.04 & 10.35 & $x_{4231}$ \\
\hline & Mechanical fixing & 0.03 & 0.04 & 8.47 & $x_{4241}$ \\
\hline & Dots & 0.04 & 0.04 & 8.48 & $x_{4222}$ \\
\hline & Adhesive mortar & 0.04 & 0.04 & 11.15 & $x_{4232}$ \\
\hline & Mechanical fixing & 0.04 & 0.04 & 9.26 & $x_{4242}$ \\
\hline & Dots & 0.05 & 0.04 & 9.51 & $x_{4223}$ \\
\hline & Adhesive mortar & 0.05 & 0.04 & 12.18 & $x_{4233}$ \\
\hline & Mechanical fixing & 0.05 & 0.04 & 10.29 & $x_{4243}$ \\
\hline & Dots & 0.06 & 0.04 & 11.45 & $x_{4224}$ \\
\hline & Adhesive mortar & 0.06 & 0.04 & 14.13 & $x_{4234}$ \\
\hline & Mechanical fixing & 0.06 & 0.04 & 12.24 & $x_{4244}$ \\
\hline & \multicolumn{5}{|l|}{ Expanded polystyrene } \\
\hline & Dots & 0.03 & 0.036 & 6.06 & $x_{4251}$ \\
\hline & Adhesive mortar & 0.03 & 0.036 & 8.04 & $x_{4261}$ \\
\hline & Mechanical fixing & 0.03 & 0.036 & 7.43 & $x_{4271}$ \\
\hline & Dots & 0.04 & 0.036 & 6.44 & $x_{4252}$ \\
\hline & Adhesive mortar & 0.04 & 0.036 & 8.42 & $x_{4262}$ \\
\hline & Mechanical fixing & 0.04 & 0.036 & 7.80 & $x_{4272}$ \\
\hline & Dots & 0.05 & 0.036 & 7.09 & $x_{4253}$ \\
\hline & Adhesive mortar & 0.05 & 0.036 & 9.07 & $x_{4263}$ \\
\hline & Mechanical fixing & 0.05 & 0.036 & 8.46 & $x_{4273}$ \\
\hline & Dots & 0.06 & 0.036 & 7.73 & $x_{4254}$ \\
\hline & Adhesive mortar & 0.06 & 0.036 & 9.71 & $x_{4264}$ \\
\hline & Mechanical fixing & 0.06 & 0.036 & 9.10 & $x_{4274}$ \\
\hline & Dots & 0.07 & 0.036 & 8.37 & $x_{4255}$ \\
\hline & Adhesive mortar & 0.07 & 0.036 & 10.35 & $x_{4265}$ \\
\hline & Mechanical fixing & 0.07 & 0.036 & 9.74 & $x_{4275}$ \\
\hline & Dots & 0.08 & 0.036 & 9.03 & $x_{4256}$ \\
\hline & Adhesive mortar & 0.08 & 0.036 & 11.01 & $x_{4266}$ \\
\hline & Mechanical fixing & 0.08 & 0.036 & 10.39 & $x_{4276}$ \\
\hline & \multicolumn{5}{|l|}{ Wood chips } \\
\hline & Mechanical fixing & 0.015 & 0.09 & 14.96 & $x_{4281}$ \\
\hline & Mechanical fixing & 0.025 & 0.09 & 16.83 & $x_{4282}$ \\
\hline & Mechanical fixing & 0.035 & 0.09 & 18.26 & $x_{4283}$ \\
\hline & Mechanical fixing & 0.05 & 0.09 & 21.00 & $x_{4284}$ \\
\hline & \multicolumn{5}{|l|}{$\begin{array}{l}\text { Agglomerate of } \\
\text { expanded cork }\end{array}$} \\
\hline & Dots & 0.025 & 0.036 & 12.99 & $x_{4291}$ \\
\hline & Mechanical fixing & 0.025 & 0.036 & 13.72 & $x_{4301}$ \\
\hline
\end{tabular}




\begin{tabular}{|c|c|c|c|c|c|}
\hline & Dots & 0.03 & 0.036 & 15.46 & $x_{4292}$ \\
\hline & Mechanical fixing & 0.03 & 0.036 & 16.19 & $x_{4302}$ \\
\hline & Dots & 0.04 & 0.036 & 17.92 & $x_{4293}$ \\
\hline & Mechanical fixing & 0.04 & 0.036 & 18.65 & $x_{4303}$ \\
\hline & Dots & 0.05 & 0.036 & 21.41 & $x_{4294}$ \\
\hline & Mechanical fixing & 0.05 & 0.036 & 22.13 & $x_{4304}$ \\
\hline & Dots & 0.06 & 0.036 & 25.29 & $x_{4295}$ \\
\hline & Mechanical fixing & 0.06 & 0.036 & 26.01 & $x_{4305}$ \\
\hline & Dots & 0.07 & 0.036 & 25.69 & $x_{4296}$ \\
\hline & Mechanical fixing & 0.07 & 0.036 & 26.42 & $x_{4306}$ \\
\hline & Dots & 0.08 & 0.036 & 26.09 & $x_{4297}$ \\
\hline & Mechanical fixing & 0.08 & 0.036 & 26.82 & $x_{4307}$ \\
\hline & \multicolumn{5}{|l|}{ Sandwich panel } \\
\hline & Mechanical fixing & 0.025 & 0.056 & 17.25 & $x_{4311}$ \\
\hline & Mechanical fixing & 0.035 & 0.056 & 18.76 & $x_{4312}$ \\
\hline & Mechanical fixing & 0.05 & 0.056 & 22.27 & $x_{4313}$ \\
\hline \multirow[t]{8}{*}{ 5. Internal panel } & Air brick $24 \times 11,5 \times 11,5$ & 0.115 & 0.49 & 23.93 & $x_{5321}$ \\
\hline & Air brick 33x16x11 & 0.11 & 0.49 & 17.74 & $x_{5331}$ \\
\hline & $\begin{array}{l}\text { Perforated brick } \\
24 \times 11,5 \times 9\end{array}$ & 0.115 & 0.76 & 23.29 & $x_{5341}$ \\
\hline & Solid Concrete block & 0.15 & 0.46 & 31.43 & $x_{5351}$ \\
\hline & $40 \times 20 \times(15$ or 20$)$ & 0.20 & 0.46 & 37.92 & $x_{5352}$ \\
\hline & Expanded clay light & 0.20 & 0.3 & 42.21 & $x_{5361}$ \\
\hline & concrete block & 0.25 & 0.3 & 53.94 & $x_{5362}$ \\
\hline & & 0.30 & 0.3 & 80.54 & $x_{5363}$ \\
\hline \multirow[t]{4}{*}{ 6. Internal coating } & Plaster & 0.008 & 0.26 & 20.47 & $x_{6371}$ \\
\hline & & 0.010 & 0.26 & 21.87 & $x_{6372}$ \\
\hline & & 0.012 & 0.26 & 23.27 & $x_{6373}$ \\
\hline & & 0.014 & 0.26 & 24.67 & $x_{6374}$ \\
\hline
\end{tabular}




\section{Appendix B. Result of the ILP problem for each scenario}

\section{Table B1}

Minimum transmittance given an interval of thickness (row) for the external wall and a maximum budget (column).

\begin{tabular}{|c|c|c|c|c|c|c|c|c|c|c|c|c|c|c|c|c|c|c|c|c|c|}
\hline & 90 & 95 & 100 & 105 & 10 & 15 & 120 & 125 & 130 & 135 & 140 & 145 & 150 & 155 & 160 & 165 & 170 & 175 & 180 & 185 & 190 \\
\hline $.24,0.25]$ & & & & & & & & 45 & 1.332 & 1.332 & 32 & 32 & 332 & 332 & 332 & 332 & 32 & 332 & 332 & 332 & .332 \\
\hline$[0.25,0.26]$ & & & & & & & & 782 & 0.782 & 0.782 & .782 & .782 & .782 & .782 & 0.782 & 0.782 & 0.782 & .782 & .782 & 0.782 & 0.782 \\
\hline$[0.26,0.27]$ & & & 322 & 305 & 299 & 709 & 698 & 0.698 & 0.698 & 0.698 & 0.698 & .698 & .698 & 0.698 & 0.698 & 0.698 & 0.698 & 0.698 & .698 & 0.698 & 0.698 \\
\hline $0.27,0.28]$ & 706 & .703 & 700 & 700 & 700 & 00 & oJ & 0.585 & 0.585 & 0.585 & .585 & .585 & .585 & .585 & 0.585 & 0.585 & 0.585 & 0.585 & .585 & 0.585 & 0.585 \\
\hline$[0.28,0.29]$ & 0.591 & 0.588 & 0.586 & 0.586 & 0.586 & 0.586 & 0.505 & 0.503 & 0.503 & 0.503 & 0.503 & 0.503 & 0.503 & 0.503 & 0.503 & 0.503 & 0.503 & 0.503 & 0.503 & 0.503 & 0.503 \\
\hline$[0.29,0.30]$ & 0.509 & 0.505 & 4 & 4 & 4 & 4 & ( & 0.441 & 0.441 & 0.441 & 0.441 & .441 & 441 & 0.441 & 0.441 & 0.441 & 0.441 & .441 & .441 & 0.441 & 0.441 \\
\hline $0.30,0.31]$ & . & . & o. & . & 178 & $7+2$ & . & 0.393 & 0.393 & S & נדנ. & 0.393 & .393 & 0.393 & 0.393 & 0.393 & 0.393 & 0.393 & 0.393 & 0.393 & 0.393 \\
\hline $0.31,0.32]$ & .483 & 395 & 395 & 0.394 & 394 & 94 & 0 & 0.354 & .354 & .354 & 354 & 354 & 354 & .354 & .354 & .354 & 0.354 & 354 & .354 & 0.354 & 0.354 \\
\hline$[0.32,0.33]$ & 0.428 & 0.356 & 0.356 & 0.355 & 0.355 & 0.355 & 0.355 & 0.355 & 0.353 & 0.353 & 0.353 & 0.353 & 0.353 & 0.353 & 0.353 & 0.352 & 0.352 & 0.352 & 0.352 & 0.352 & 0.352 \\
\hline$[0.3$ & 0.382 & 255 & 54 & 53 & 53 & 2 & 4 & 3 & 3 & 0 & 3 & 3 & +3 & 43 & 3 & 43 & 43 & 43 & 43 & 343 & 0.343 \\
\hline .35$]$ & 0.397 & & & & & & & 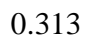 & 0.313 & 0.313 & 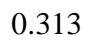 & 0.313 & 0.313 & 3 & 0.313 & 0.313 & 3 & 3 & 3 & 3 & 313 \\
\hline$[0.35,0.36]$ & 0.358 & 0.314 & 0.314 & 0.313 & 0.313 & 313 & 313 & 0.313 & 0.312 & 0.312 & 0.312 & 0.312 & 0.312 & 0.312 & 0.312 & 0.311 & 0.311 & 0.311 & 0.311 & 0.311 & 0.311 \\
\hline$[0.36,0.37]$ & 0.334 & 0.314 & 0.312 & 0.312 & 0.311 & 0.311 & 0.297 & 0.296 & 0.296 & 0.296 & 0.296 & 0.296 & 0.296 & 0.296 & 0.296 & 0.296 & 0.296 & 0.296 & 0.296 & 0.296 & 0.296 \\
\hline$[0.37,0.38]$ & 0.351 & 0.297 & 0.297 & 0.296 & 296 & 296 & 0.296 & 0.296 & 0.295 & 0.295 & 0.295 & 0.295 & 0.295 & 0.295 & 0.295 & 0.295 & 0.295 & 0.295 & 0.295 & 0.295 & 0.295 \\
\hline$[0.38,0.39]$ & 0.319 & & 96 & & & & & 91 & 0.231 & 0.231 & 0.291 & 0.291 & 91 & 91 & 0.291 & 0.291 & 0.291 & 0.291 & 0.291 & 0.291 & 0.291 \\
\hline$[0.39,0.40]$ & 0.297 & 0.292 & 0.292 & 0.292 & 0.292 & 0.292 & 0.271 & 0.269 & 0.269 & 0.269 & 0.269 & 0.269 & 0.269 & .269 & 0.269 & 0.269 & 0.269 & 0.269 & 0.269 & 0.269 & 0.269 \\
\hline$[0.40,0.41]$ & 0.298 & 0.270 & 0.270 & 0.270 & 0.270 & 0.270 & 0.270 & 0.270 & 0.269 & 0.269 & 0.269 & 0.269 & 0.269 & 0.269 & 0.269 & 0.268 & 0.268 & 0.268 & 0.268 & 0.268 & 0.268 \\
\hline$[0.41,0.42]$ & 0.282 & 0.270 & 0.269 & 0.269 & 0.268 & 0.268 & .255 & 0.254 & 0.254 & 0050 & 0.254 & 0.254 & 0.254 & 0.254 & 0.254 & 0.254 & 0.254 & 0.254 & 0.254 & 0.254 & 0.254 \\
\hline$[0.42,0.43]$ & 0.300 & 0.255 & 0.255 & 0.255 & 0.255 & .255 & 0.255 & 0.255 & 0.254 & 0.254 & 0.254 & 0.254 & 0.254 & 0.254 & 0.254 & 0.253 & 0.253 & 0.253 & 0.253 & 0.253 & 0.253 \\
\hline$[0.43,0.44]$ & 0.211 & 0.255 & 0.234 & 0.254 & 0.253 & 0.253 & 0.253 & 0.253 & 0.255 & 0.253 & 0.255 & 0.253 & 0.253 & 0.253 & 0.253 & 0.253 & 0.255 & 0.253 & 0.253 & 0.253 & 0.253 \\
\hline$[0.44,0.45]$ & 0.257 & 0.256 & 0.256 & 0.253 & 0.253 & 0.253 & 0.253 & 0.253 & 0.253 & 0.253 & 0.253 & 0.253 & 0.253 & 0.253 & 0.253 & 0.253 & 0.253 & 0.253 & 0.253 & 0.253 & 0.253 \\
\hline
\end{tabular}




\begin{tabular}{|c|c|c|c|c|c|c|c|c|c|c|c|c|c|c|c|c|c|c|c|c|c|}
\hline$[0.45,0.46]$ & 0.261 & 0.256 & 0.256 & 0.255 & 0.255 & 0.255 & 0.255 & 0.255 & 0.255 & 0.248 & 0.248 & 0.248 & 0.248 & 0.248 & 0.248 & 0.248 & 0.248 & 0.248 & 0.248 & 0.248 & 0.248 \\
\hline$[0.46,0.47]$ & 0.244 & 0.242 & 0.242 & 0.242 & 0.242 & 0.242 & 0.242 & 0.242 & 0.242 & 0.242 & 0.242 & 0.242 & 0.242 & 0.242 & 0.242 & 0.242 & 0.242 & 0.242 & 0.242 & 0.242 & 0.242 \\
\hline$[0.47,0.48]$ & & 0.242 & 0.242 & 0.242 & 0.241 & 0.241 & 0.241 & 0.241 & 0.241 & 0.241 & 0.241 & 0.241 & 0.241 & 0.241 & 0.241 & 0.241 & 0.241 & 0.241 & 0.241 & 0.241 & 0.241 \\
\hline$[0.48,0.49]$ & & & & 0.250 & 0.250 & 0.249 & 0.249 & 0.244 & 0.243 & 0.242 & 0.242 & 0.242 & 0.241 & 0.241 & 0.241 & 0.241 & 0.241 & 0.241 & 0.241 & 0.241 & 0.241 \\
\hline$[0.49,0.50]$ & & & & 0.254 & 0.249 & 0.249 & 0.241 & 0.241 & 0.241 & 0.241 & 0.241 & 0.241 & 0.241 & 0.241 & 0.241 & 0.241 & 0.241 & 0.241 & 0.240 & 0.240 & 0.240 \\
\hline$[0.50,0.51]$ & & & & 0.237 & 0.237 & 0.236 & 0.236 & 0.236 & 0.236 & 0.236 & 0.236 & 0.229 & 0.229 & 0.229 & 0.229 & 0.229 & 0.229 & 0.229 & 0.229 & 0.229 & 0.229 \\
\hline$[0.51,0.52]$ & & & & & 0.236 & 0.236 & 0.229 & 0.229 & 0.229 & 0.229 & 0.229 & 0.229 & 0.229 & 0.229 & 0.229 & 0.229 & 0.229 & 0.229 & 0.228 & 0.228 & 0.228 \\
\hline$[0.52,0.53]$ & & & & & 0.262 & 0.242 & 0.229 & 0.228 & 0.228 & 0.228 & 0.228 & 0.228 & 0.228 & 0.228 & 0.228 & 0.228 & 0.228 & 0.228 & 0.228 & 0.228 & 0.228 \\
\hline$[0.53,0.54]$ & & & & & 0.244 & 0.231 & 0.230 & 0.230 & 0.230 & 0.230 & 0.230 & 0.230 & 0.230 & 0.229 & 0.229 & 0.229 & 0.229 & 0.229 & 0.229 & 0.229 & 0.229 \\
\hline$[0.54,0.55]$ & & & & & 0.248 & 0.234 & 0.230 & 0.230 & 0.229 & 0.229 & 0.229 & 0.229 & 0.229 & 0.229 & 0.229 & 0.229 & 0.229 & 0.229 & 0.229 & 0.229 & 0.229 \\
\hline$[0.55,0.56]$ & & & & & 0.232 & 0.220 & 0.219 & 0.219 & 0.219 & 0.219 & 0.219 & 0.219 & 0.219 & 0.219 & 0.219 & 0.219 & 0.219 & 0.219 & 0.219 & 0.219 & 0.219 \\
\hline$[0.56,0.57]$ & & & & & & 0.231 & 0.219 & 0.219 & 0.218 & 0.218 & 0.218 & 0.218 & 0.218 & 0.218 & 0.218 & 0.218 & 0.218 & 0.218 & 0.218 & 0.218 & 0.218 \\
\hline$[0.57,0.58]$ & & & & & & & & 0.238 & 0.221 & 0.220 & 0.220 & 0.220 & 0.220 & 0.219 & 0.219 & 0.219 & 0.219 & 0.219 & 0.219 & 0.219 & 0.219 \\
\hline$[0.58,0.59]$ & & & & & & & & 0.223 & 0.222 & 0.222 & 0.221 & 0.221 & 0.220 & 0.219 & 0.219 & 0.219 & 0.219 & 0.219 & 0.219 & 0.219 & 0.219 \\
\hline$[0.59,0.60]$ & & & & & & & & 0.226 & 0.222 & 0.221 & 0.221 & 0.221 & 0.221 & 0.221 & 0.221 & 0.221 & 0.220 & 0.220 & 0.220 & 0.220 & 0.220 \\
\hline$[0.60,0.61]$ & & & & & & & & 0.212 & 0.211 & 0.211 & 0.211 & 0.211 & 0.211 & 0.211 & 0.211 & 0.211 & 0.211 & 0.211 & 0.211 & 0.211 & 0.211 \\
\hline$[0.61,0.62]$ & & & & & & & & & 0.211 & 0.211 & 0.211 & 0.211 & 0.211 & 0.211 & 0.211 & 0.211 & 0.211 & 0.211 & 0.211 & 0.211 & 0.211 \\
\hline$[0.62,0.63]$ & & & & & & & & & & & & & 0.247 & 0.227 & 0.212 & 0.212 & 0.211 & 0.211 & 0.211 & 0.211 & 0.211 \\
\hline$[0.63,0.64]$ & & & & & & & & & & & & & 0.232 & 0.214 & 0.214 & 0.212 & 0.212 & 0.212 & 0.212 & 0.212 & 0.212 \\
\hline$[0.64,0.65]$ & & & & & & & & & & & & & & 0.216 & 0.214 & 0.214 & 0.213 & 0.213 & 0.213 & 0.213 & 0.213 \\
\hline$[0.65,0.66]$ & & & & & & & & & & & & & & 0.204 & 0.204 & 0.204 & 0.204 & 0.204 & 0.204 & 0.204 & 0.204 \\
\hline$[0.66,0.67]$ & & & & & & & & & & & & & & & 0.204 & 0.204 & 0.204 & 0.204 & 0.204 & 0.204 & 0.204 \\
\hline$[0.67,0.68]$ & & & & & & & & & & & & & & & & & & & & & 0.205 \\
\hline$[0.68,0.69]$ & & & & & & & & & & & & & & & & & & & & & 0.205 \\
\hline
\end{tabular}




\section{References}

[1] Directive 2010/31/EU of the European Parliament and the Council of 19 May 2010 on the energy performance of buildings. http://eur-lex.europa.eu/LexUriServ/LexUriServ.do?uri=OJ:L:2010:153: 0013:0035:en:PDF (2017)

[2] European Commission. Communication from the Commission to the European Parliament, the Council, The European Economic and Social Committee and the Committee of the Regions. Energy Efficiency Plan $2011(2011)$.

[3] Boosting building renovation. What potential and value for Europe? Study for the ITRE Committee. http://www.europarl.europa.eu/RegData/etudes/STUD/2016/587326/IPOL_STU(2016)587326_EN.pdf (2017).

[4] L. Liu, H. Li, A. Lazzaretto, G. Manente, C. Tong, Q. Liu, N. Li, The development history and prospects of biomass-based insulation materials for buildings, Renew. Sustain. Energy Rev. 69 (2017) 912-932.

[5] EPBD 31/2010. Directive on Energy performance of Building recast, European Parliament and European Council, Bruxelles (2010).

[6] IEA International Energy Agency, https://www.iea.org (2017)

[7] D.E.M. Bond, W.W. Clark, M. Kimber, Configuring wall layers for improved insulation performance, Appl. Energy 112 (2013) 235-245

[8] R. McMullan, Environmental Science in Building, Ed. Palgrave Macmillan, Basingtoke, 2012.

[9] F. Ascione, N. Bianco, C. De Satio, G.M. Mauro, G.P. Vanoli, A new methodology for cost-optimal analysis by means of the multi-objective optimization of building energy performance, Energy Build. 88 (2015) 78-90.

[10] F. Ascione, N. Bianco, R.F. De Masi, G.M. Mauro, G.P. Vanoli, Design of the building envelope: A novel multi-objective approach for the optimization of energy performance and thermal comfort, Sustainability 7 (2015) 10809-10836.

[11] I. Mandilaras, I. Atsonios, G. Zannis, M. Founti, Thermal performance of a building envelope incorporating ETICS with vacuum insulation panels and EPS, Energy Build. 85 (2014) 654-665.

[12] I. Guillén, V. Gómez-Lozano, J.M. Fran, P.A. López-Jiménez, Thermal behavior analysis of different multilayer façade: Numerical model versus experimental prototype, Energy Build. 79 (2014) 184-190.

[13] U. Eicker, E. Demir, D. Gürlich, Strategies for cost efficient refurbishment and solar energy integration in European Case Study buildings, Energy Build. 102 (2015) 237-249.

[14] C. Ahern, B. Norton, B. Enright, The statistical relevance and effect of assuming pessimistic default overall thermal transmittance coefficients on dwelling energy performance certification quality in Ireland, Energy Build. 127 (2016) 268-278.

[15] P.A. Fokaides, A.M. Papadopoulos, Cost-optimal insulation thickness in dry and mesothermal climates: Existing models and their improvement, Energy Build. 68 (2014) 203-212.

[16] A. Schrijver, Theory of linear and integer programming. Ed. John Wiley \& Sons, West Sussex, 2000.

[17] J.J. Salazar, Programación Matemática, Ed. Díaz de Santos, Tenerife, 2001.

[18] M. Bojic, N. Trifunovic, Mixed integer linear programming optimization of heat distribution within a local heating system, Indoor Built Environ. 6 (1997) 282-290. 
[19] M. Bojic, N. Trifunovic, Linear programming optimization of heat distribution in a district-heating system by valve adjustments and substation retrofit, Build. Environ. 35 (2000) 151-159.

[20] G. Privitera, A.R. Dayb, G. Dhesic, D. Long, Optimising the installation costs of renewable energy technologies in buildings: A Linear Programming approach, Energy Build. 43 (2011) 838-843.

[21] A. Ashouri, S.S. Fux, M.J. Benz, L. Guzzella, Optimal design and operation of building services using mixed-integer linear programming techniques, Energy 59 (2013) 365-376.

[22] K.B. Lindberg, G. Doorman, D. Fischerc, M. Korpås, A. Ånestad, I. Sartori, Methodology for optimal energy system design of Zero Energy Buildings using mixed-integer linear programming, Energy Build. 127 (2016) 194-205.

[23] A.S.O. Ogunjuyigbe, T.R. Ayodele, O.E. Oladimeji, Management of loads in residential buildings installed with PV system under intermittent solar irradiation using mixed integer linear programming, Energy Build. 130 (2016) 253-271.

[24] A. Brandão, M. Duarte, A. Manso, A. Cabaço, EPDB cost-optimal methodology: Application to the thermal rehabilitation of the building envelope of a Portuguese residential reference building, Energy Build. 111 (2016) 12-25.

[25] IVE Instituto Valenciano de la Edificación, Catálogo de elementos constructivos v.03.60, 2010

[26] Generador de precios de la construcción. España. CYPE Ingenieros, S.A., http://www.generadordeprecios.info (2017)

[27] S. Schiavoni, F. D’Alessandro, F. Bianchi, F. Asdrubali, Insulation materials for the building sector: A review and comparative analysis, Renew. Sustain. Energy Rev. 62 (2016) 988-1011.

[28] CTE. Código Técnico de la Edificación (Spanish Technical Building Act). Documento Básico de Ahorro de Energía (Basic Document for Energy Saving). Version of 2013 with comments of 2016. http://www.codigotecnico.org/images/stories/pdf/ahorroEnergia/DccHE.pdf (2017).

[29] Wolfram, Mathematica, http://www.wolfram.com/mathematica (2017). 